\title{
Identifying foods with good nutritional quality and price for the Opticourses intervention research project
}

\author{
Christophe Dubois, Marion Tharrey and Nicole Darmon* \\ INRA 11 10, CIRAD, SupAgro, CIHEAM-IAMM, MOISA (Markets, Organizations, institutions and Strategies of \\ Actors), Campus Inra-SupAgro de la Gaillarde, 2 place Pierre Viala - Bât. 26, 34060 Montpellier Cedex 2, France
}

Submitted 22 November 2016: Final revision received 16 May 2017: Accepted 20 July 2017: First published online 14 September 2017

\begin{abstract}
Objective: People on a limited budget want to know the 'good price' of foods. Here we report the methodology used to produce an educational tool designed to help recognize foods with good nutritional quality and price, and assess the validity and relevancy of the tool.

Design: A 'Good Price Booklet' presenting a list of foods with good nutritional quality and price was constructed. The validity of the in-booklet prices was assessed by comparing them with prices actually paid by households from the Opticourses project. The relevancy of the booklet tool was assessed by semi-structured interviews with Opticourses participants.

Setting: Socio-economically disadvantaged neighbourhoods of Marseille, France. Subjects: Ninety-one participants collected household food-purchase receipts over a 1-month period.

Results: Based on the French food database, foods with higher-than-median nutritional quality were identified. After grouping similar foods, 100 foods were selected and their corresponding in-booklet prices were derived based on the distribution of average national prices by food group. Household food purchases data revealed that of the 2386 purchases of foods listed in the booklet, $67 \cdot 1 \%$ were bought at prices lower than the in-booklet prices. Nineteen semi-structured interviews showed that participants understood the tool and most continued using it more than a month after the intervention.

Conclusions: A method was developed to ease the identification of foods with good nutritional quality and price. The Good Price Booklet is an effective tool to help guide people shopping on a low budget.
\end{abstract}

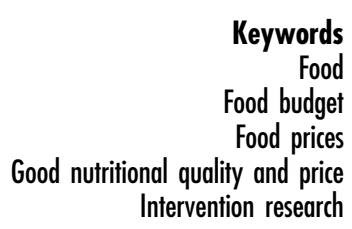

Studies suggest that the cost of food helps explain social inequalities in nutrition $^{(1-3)}$, partly due to the direct relationship between diet quality and diet cost ${ }^{(4,5)}$. Energydense nutrient-poor foods are often the cheapest sources of energy $^{(6)}$, making it more difficult for a person with a very limited budget to get a balanced $\operatorname{diet}^{(7,8)}$. However, eating healthily at low cost is achievable by making nutritionally optimal choices that target affordable nutrient-rich foods ${ }^{(9-13)}$. Diet modelling approaches on French data showed that it is possible to get a balanced food basket with a modest budget of at least $€ 3 \cdot 50$ /person per $\mathrm{d}^{(8,14)}$ on the condition that foods with good nutritional quality for price (NQP) - assessed as the relationship between nutrient profile and average national price - are selected ${ }^{(12)}$. In short, getting a balanced diet on a small budget is difficult, but not impossible. But is this realistic, and how do we translate theory into practice? To find out, the Opticourses intervention (www.opticourses.fr) was launched in 2012 in the northern neighbourhoods of Marseille (France) following two pilot actions conducted in 2010 and 2011. Within the framework of a multi-partner, territorialcommunity participative approach, the Opticourses project featured supply-side and demand-side strands, both aimed at increasing purchases of good-NQP foods by financially struggling households. The demand side of the intervention involved workshops on diet and budget attended on a voluntary basis by local inhabitants responsible for their household's food purchases ${ }^{(15)}$. The supply side was based on a social marketing intervention that aimed to make good-NQP foods accessible, visible and attractive in shops in the target neighbourhoods ${ }^{(16)}$.

Consistent with the existing literature, early exploration of the factors driving food purchases in the Opticourses population revealed that price was a major concern ${ }^{(16)}$ and that participants expressed a strong desire to know the 'good price' for foods. This popular notion referred to an affordable price, given a low food budget, within the range of market prices ${ }^{(17)}$. The research team thus made it 
its goal to operationalize this popular notion by coconstructing an educational tool called the 'Good Price Booklet', designed to help participants make sound combined nutritional and budgetary choices at the time of purchase.

The aim of the present paper is to describe the methodology used to produce the Good Price Booklet and to provide quantitative and qualitative assessments of its applicability, perception and use by the target public.

\section{Materials and methods}

\section{Study design and population}

Details and characteristics of the Opticourses nutrition intervention (2012-2014) have been described elsewhere $^{(15)}$. Participants facing financial problems and willing to participate in the 'demand' strand of the intervention were asked to provide a detailed record of foods entering their household over a 1-month period. In-depth interviews were also conducted to understand the factors driving food purchases in this population ${ }^{(16)}$.

\section{Methodology to create the Good Price Booklet}

Food composition and price databases

The INCA2 food composition table covering 1343 foods declared as having been consumed over one week by a representative sample of 2624 adults who participated in the French national INCA2 survey in 2006-2007 was used. In addition to energy content and about thirty nutritional components, the composition table included two variables obtained during a previous study ${ }^{(18)}$ : one column for added sugars and one column for average national prices (calculated on the basis of purchases made by the 2006 Kantar consumer panel). The food composition table gives nutritional values for foods as consumed and average national prices are expressed in $€ / 100 \mathrm{~g}$ of food as consumed. However, here we needed to determine the price of foods as purchased, as this is the only relevant information to communicate to participants. We therefore used correction coefficients enabling us to move from price of food consumed to price of purchase (e.g. the average price of $100 \mathrm{~g}$ of cooked pasta was multiplied by a coefficient of 3 to obtain the average price of $100 \mathrm{~g}$ of raw pasta).

\section{SAIN and LIM calculations}

SAIN and LIM are indicators that estimate foods' positive and negative aspects, respectively ${ }^{(19)}$. SAIN estimates the adequacy, per $418 \mathrm{~kJ}$ ( $100 \mathrm{kcal})$ of food, of the recommended daily intake of protein, vitamin $\mathrm{C}$, fibre, Ca and Fe. LIM estimates the average excess, per $100 \mathrm{~g}$ of food, of $\mathrm{Na}$, SFA and added simple sugars. The ratio SAIN:LIM gives a single indicator of nutritional quality: the higher the ratio of a food, the better its nutritional quality ${ }^{(12)}$. In the specific case of a food having a LIM of less than 1, we consider that the SAIN:LIM is equal to the food's SAIN. SAIN:LIM was calculated for all foods in the INCA2 composition table.
Definition of foods with good nutritional quality

The next stage of the analysis was carried out on a reduced composition table covering all the foods of the INCA2 table including fortified foods and foods described as 'generic' (e.g. 'non-specified fruit' or 'non-specified cheese') but excluding ready-made meals (due to their huge variability in composition), alcoholic beverages and non-caloric beverages. Foods whose SAIN:LIM was higher than the median calculated in this reduced table were considered to be of good nutritional quality.

\section{Determination of the good prices for foods of good nutritional quality}

Each food of good nutritional quality was then attributed a good price, defined as the price below which the food can be considered relatively inexpensive. To determine this price, two variables were used: (i) the average national price of the food as purchased; and (ii) its 'limit price', defined as equal to the value of the first price tertile of the group to which it belongs. For each food, the average national price was then compared against the limit price and the following rule was applied: when average national price was below limit price, then average national price was selected as the good price; if not, limit price was chosen instead.

\section{Selection and grouping of foods of good nutritional quality and price for the Good Price Booklet}

Based on the calculations described above, a list of foods with good nutritional quality and price was established to be communicated to workshop participants in the form of an educational tool called the Good Price Booklet. To avoid communicating prices that were unrealistic (too low regarding marketplace reality), it was decided to present only those foods whose average national price was no more than 2.5 times higher than the limit price. The ratio of 2.5 was chosen because it is the average ratio observed between the price of 'brand-name' foods and the price of the cheapest foods sold under the same name ${ }^{(9,10)}$.

An expert appraised the list of foods to avoid potential repetitions in the composition table (e.g. baked potato and boiled or steamed potato) and to group together similar foods under a single designation in accordance with their purchased form (e.g. potato). In that case, the good price indicated in the booklet was the average of good prices of the different foods that have been grouped together.

The selected foods were classified according to supermarket shelves. For some foods, booklet price was calculated by unit as sold in stores (e.g. for one grapefruit or one lettuce).

\section{Assessment \\ Quantitative assessement of the in-booklet prices Opticourses participants ( $n$ 91) were asked to collect all food-purchase receipts for their household over a 1-month period. Purchase-receipt protocol training and data}


collection were previously described by Marty et $a l^{(15)}$. For each food item, information from receipts (i.e. date of purchase, corresponding INCA2 food name and code, quantity and price) were entered into a food purchases database. The validity of the food prices listed in the booklet was assessed by quantifying the percentage of purchases bought at a price lower than the in-booklet price, by supermarket shelf category and for the whole food list.

\section{Qualitative assessment of the Good Price Booklet}

As part of the effort to evaluate the Opticourses intervention, nineteen semi-structured interviews were conducted with participants after the workshops by an external evaluator. The interview guide contained questions on the tools used during the workshops, particularly the Good Price Booklet.

\section{Results}

Opticourses bousebolds: descriptive characteristics Sociodemographic characteristics of the Opticourses households are given in Table 1. Mean household size was 3.41 (range: 1-8), including two children on average (range: 0-6). Almost half of the households (48.2\%) were in a precarious financial situation and one-third (36.5\%) declared severe financial difficulties. Each household shopped at an average of five different stores while collecting receipts, and price was reported as the most important determinant of food purchases.

\section{List of foods featuring in the Good Price Booklet}

The different stages in the process of identifying the foods with good nutritional quality and price are summarized in Fig. 1. The reduced INCA2 table with ready-made meals and alcoholic and non-caloric beverages pre-eliminated contained 1054 foods. The median SAIN:LIM was then calculated on this reduced table, and foods with SAIN:LIM lower than this median were discarded, resulting in a list of 527 foods of high nutritional quality. Then foods with an average national price 2.5 times greater than their limit

Table 1 Sociodemographic characteristics of Opticourses households ( $n$ 91) from socio-economically disadvantaged neighbourhoods of Marseille, France, 2012-2014

\begin{tabular}{lcc}
\hline & Mean or \% & SD \\
\hline Respondent age (years) & $48 \cdot 1$ & 10.1 \\
No. of household members & 3.41 & 1.97 \\
No. of children & 1.70 & 1.68 \\
No. of stores frequented & 4.85 & 3.22 \\
Female respondents (\%) & 75.8 & - \\
Food aid recipients (\%) & 11.0 & - \\
Financial situation (\%) & & \\
$\quad$ Stable & 15.3 & - \\
Precarious & 48.2 & - \\
Severe difficulties & 36.5 & - \\
\hline
\end{tabular}

price were eliminated (mostly expensive foods such as shellfish, game meat, berries and nuts). Among the remaining foods ( $n$ 404), similar items were then grouped together under the same designation, resulting in 153 foods classified according to supermarket shelf. Table 2 presents the list of foods with good nutritional quality and price selected and included in the booklet. For example, for generic foods, the in-booklet price is €1.94/ $\mathrm{kg}$ for fresh vegetables, €2.42/kg for tinned or frozen vegetables, $€ 1 \cdot 80 / \mathrm{kg}$ for fresh fruits, $€ 2 \cdot 35 / \mathrm{kg}$ for pasta and rice, $€ 4 \cdot 34 / \mathrm{kg}$ for legumes, $€ 2 \cdot 07 / \mathrm{kg}$ for dairy products and $€ 9 \cdot 56 / \mathrm{kg}$ for meat and fish (Table 2).

\section{Creation of the Good Price Booklet}

The Good Price Booklet was created in collaboration with a graphic designer (Fig. 2). This educational tool is presented in the form of a small brochure in payment-card format. It was distributed to participants during the Opticourses intervention workshops to help them spot foods and their corresponding good prices when shopping for groceries.

The flyleaf of the booklet carries the slogan 'Good for my health and good for my wallet'. The second page carries the statement: 'All these foods are of good nutritional quality. If you find them cheaper than the price indicated, it's a bargain for eating healthily and cheaply. If you find them at a price higher than the price indicated, you can buy them anyway as they are all of good nutritional quality'. Olive oil and walnuts are present in the

INCA2 table of the composition of foods ( $n$ 1343)

Elimination of ready-made meals, alcoholic beverages and non-caloric beverages

Reduced INCA2 table of the composition of foods ( $n$ 1054)

$$
\begin{aligned}
& \text { Elimination of foods with a } \\
& \text { SAIN:LIM }<\text { median } \\
& \text { Calculation of limit price for each food }
\end{aligned}
$$

Foods of good nutritional quality ( $n 527)$

Elimination of foods whose average national price is 2.5 times higher than the limit price (except for olive oil and walnuts)

\author{
Foods with good nutritional quality and price ( $n$ 404) \\ Grouping together similar foods under a \\ single designation \\ Dividing into categories depending on \\ supermarket shelves \\ Good Price Booklet ( $n$ 153)
}

Fig. 1 Flowchart showing how foods were selected for the Good Price Booklet (INCA2, second French national cross-sectional dietary study; SAIN, indicator that estimates foods' positive aspects; LIM, indicator that estimates foods' negative aspects; limit price for a given food corresponds to the first tertile of the mean prices of foods in the group to which that food belongs) 
Table 2 List of foods with good nutritional quality presented in the Good Price Booklet with their 'good price' (€/kg or $€ /$ article), Opticourses intervention research project conducted in socio-economically disadvantaged neighbourhoods of Marseille, France, 2012-2014

\begin{tabular}{|c|c|c|c|c|c|}
\hline Shelf & Food & Good price $(€ / \mathrm{kg})$ & Shelf & Food & Good price $(€ / \mathrm{kg})$ \\
\hline \multirow[t]{23}{*}{ Vegetables } & & & Grains & & \\
\hline & Aubergine & $1 \cdot 76$ & & Wheat & 2.35 \\
\hline & Avocado & $0.44 \ddagger \ddagger$ & & Couscous & $2 \cdot 15$ \\
\hline & Beetroot & 2.06 & & Pasta & 2.09 \\
\hline & Chard & 1.99 & & Wholemeal pasta & 2.35 \\
\hline & Broccoli & $2 \cdot 18$ & & Polenta/cornmeal & $2 \cdot 25$ \\
\hline & Carrot & $1 \cdot 12$ & & Rice & $2 \cdot 31$ \\
\hline & Celery/celeriac & 1.70 & & Wholemeal rice & 2.35 \\
\hline & Mushroom & 1.70 & Potato & & \\
\hline & Cabbage* $^{\star}$ & 1.74 & & Potato & 1.28 \\
\hline & Cucumber & $0.49 \neq \ddagger$ & & Dried mashed potato & 1.66 \\
\hline & Courgette & 1.78 & & Potato gnocchi & 2.35 \\
\hline & Chicory & 1.81 & Legumes & & \\
\hline & Spinach & 1.74 & & Dry kidney/white beans & $5 \cdot 19$ \\
\hline & Corn on the cob & $0.40 \ddagger \ddagger$ & & Dry lentils & 3.85 \\
\hline & Turnip & 1.47 & & Dry split peas & 3.48 \\
\hline & Onion & 2.07 & & Dry chickpeas & $4 \cdot 83$ \\
\hline & Leek & 1.70 & Tinned vegetables & & \\
\hline & Pepper & 2.06 & & Carrots & 2.42 \\
\hline & Pumpkin & 1.70 & & Celery/celeriac & 2.42 \\
\hline & Radish (bunch) & $0.72 \ddagger \ddagger$ & & Mushrooms & 2.42 \\
\hline & Lettuce $†$ & $0.86 \neq \ddagger$ & & Sauerkraut without garnish & 2.42 \\
\hline & Tomato & $2 \cdot 18$ & & Green beans & 2.42 \\
\hline \multirow[t]{19}{*}{ Fruits } & & & & Diced mixed vegetables & $2 \cdot 19$ \\
\hline & Apricot & $2 \cdot 18$ & & Sweetcorn & 2.42 \\
\hline & Pineapple & $1.89 \ddagger \ddagger$ & & Peas with or without carrots & 2.42 \\
\hline & Banana & 1.39 & & Ratatouille & 2.42 \\
\hline & Lemon & $2 \cdot 18$ & Tinned tomatoes & & \\
\hline & Clementine/mandarin & 1.70 & & Tomato concentrate & 1.77 \\
\hline & Dried fruit $\ddagger$ & 3.90 & & Tomato sauce & 3.01 \\
\hline & Kiwi & $0.16 \neq \ddagger$ & & Tomatoes & 1.89 \\
\hline & Melon & $1.70 \ddagger \ddagger$ & Tinned legumes & & \\
\hline & Plum & $2 \cdot 18$ & & Kidney/white beans & $2 \cdot 67$ \\
\hline & Nectarine/peach & $2 \cdot 18$ & & Lentils & 1.79 \\
\hline & Walnut§ & - & & Chickpeas & 1.97 \\
\hline & Orange & 1.23 & Tinned fish & & \\
\hline & Grapefruit & $0.64 \ddagger \ddagger$ & & Cod liver & 9.56 \\
\hline & Watermelon & 0.73 & & Mackerel & 8.74 \\
\hline & Pear & 2.06 & & Sardine & 7.94 \\
\hline & Apple & 1.52 & & Tuna & $8 \cdot 36$ \\
\hline & Greengage plum & $2 \cdot 18$ & Soup & & \\
\hline & Grape & $2 \cdot 30$ & & Carton of vegetable soup & $2 \cdot 20$ \\
\hline \multirow[t]{14}{*}{ Fish } & & & & Powdered vegetable soup & 1.28 \\
\hline & Anchovy & 6.69 & Juice & & \\
\hline & Sea bream & 6.69 & & Pure fruit juice & $1 \cdot 20$ \\
\hline & Haddock/smoked haddock & 9.56 & Oils \& fats & & \\
\hline & Pollock, coley, hake & $6 \cdot 69$ & & Rapeseed oil & 1.42 \\
\hline & Mackerel & 6.85 & & Walnut oil & 3.01 \\
\hline & Mullet & 7.64 & & Olive oil§ & - \\
\hline & Perch & $7 \cdot 17$ & & Sunflower oil & 1.22 \\
\hline & Rock salmon & 8.60 & & Blended oil & $2 \cdot 18$ \\
\hline & Sardine & $5 \cdot 73$ & & Margarine & 3.01 \\
\hline & Salmon & 8.60 & Breakfast cereals & & \\
\hline & Cuttlefish & 7.64 & & Oat flakes & 3.60 \\
\hline & Tuna & 8.60 & & Muesli & 2.35 \\
\hline & Rainbow trout & $7 \cdot 17$ & Sweet products & & \\
\hline \multirow{14}{*}{ Meat } & & & & Fruit compote & 2.42 \\
\hline & Offal (poultry, beef, pork) & $5 \cdot 71$ & & Fruit salad & 1.94 \\
\hline & Chicken breast & 9.56 & & Custard & 2.74 \\
\hline & Chicken thigh & 4.96 & & Chocolate/vanilla pudding§§ & 3.38 \\
\hline & Turkey cutlet & $9 \cdot 24$ & & Rice pudding & 3.87 \\
\hline & Rabbit (whole) & 6.69 & & Gingerbread & 3.90 \\
\hline & Chicken (whole) & 5.09 & Frozen vegetables & & \\
\hline & Ground beef, $5 \%$ fat & 9.56 & & Courgette & 2.42 \\
\hline & Ground beef, $10 \%$ fat & $8 \cdot 74$ & & Spinach & 2.42 \\
\hline & Beef, high quality cuts $\|$ & 9.15 & & Green beans & 1.88 \\
\hline & Beef, other cuts & $6 \cdot 11$ & & Ratatouille & 2.42 \\
\hline & Turkey & $7 \cdot 80$ & Frozen potato & & \\
\hline & Pork (lean tenderloin, joint) & 8.49 & & Potato & 1.76 \\
\hline & Veal $^{* \star}$ & $9 \cdot 56$ & & & \\
\hline
\end{tabular}


Table 2 Continued

\begin{tabular}{|c|c|c|c|c|c|}
\hline Shelf & Food & Good price (€/kg) & Shelf & Food & Good price $(€ / \mathrm{kg})$ \\
\hline & & & Frozen fish & & \\
\hline \multirow[t]{2}{*}{ Processed meat } & & & & Seafood cocktail & 9.56 \\
\hline & $\begin{array}{l}\text { Black sausage } \\
\text { Cooked ham }\end{array}$ & $\begin{array}{l}7.25 \\
\mathbf{9 . 2 7}\end{array}$ & & $\begin{array}{l}\text { Pollock, coley, hake } \\
\text { Salmon }\end{array}$ & $\begin{array}{l}6.69 \\
8.60\end{array}$ \\
\hline \multirow[t]{2}{*}{ Eggs } & & & Frozen meat & & \\
\hline & Egg & $0 \cdot 16 \neq \ddagger$ & & Chicken thigh & 4.96 \\
\hline \multirow{9}{*}{ Dairy } & & & & Ground beef, $5 \%$ fat & 9.56 \\
\hline & Milk & 0.95 & & Ground beef, $10 \%$ fat & 8.74 \\
\hline & Flavoured milk & 1.63 & & Turkey & 7.80 \\
\hline & Fermented milk drink & 1.72 & & Pork (lean tenderloin, joint) & 8.49 \\
\hline & Fromage blanc & $2 \cdot 72$ & Generic & & \\
\hline & Petits suisses & 2.47 & & Fresh vegetables & 1.94 \\
\hline & Flavoured yoghurt & $2 \cdot 38$ & & Fresh fruit & 1.80 \\
\hline & Fruit yoghurt & $2 \cdot 38$ & & Tinned vegetables & 2.42 \\
\hline & Plain yoghurt & 1.97 & & Frozen vegetables & $2 \cdot 42$ \\
\hline \multirow{5}{*}{ Bread } & & & & Fish & $9 \cdot 56$ \\
\hline & Rusk or toasted bread†† & 2.35 & & Meat & 9.56 \\
\hline & Wholemeal bread & 2.35 & & Dairy \|\| & 2.07 \\
\hline & Rye bread, wholegrain bread & 2.35 & & Pasta, rice & 2.35 \\
\hline & & & & Legumes & 4.34 \\
\hline
\end{tabular}

In bold are foods whose 'good price' is based on the limit price rather than average national price.

*Green, white, Brussels sprouts, red, cauliflower.

†Lettuce, escarole, lamb's lettuce, curly endive.

$\ddagger$ Apricot, banana, date, prune, fig.

§'Although expensive, moderate consumption is good for your health'.

|lJoint, beefsteak.

IFor bourguignon, stews or braising.

${ }^{\star *}$ Chunks for braising, cutlet, joint.

††Wholemeal or wholegrain.

$\ddagger \ddagger$ Good price/unit ( $€$ /article).

$\S \S$ Tinned or fresh.

|| || Yoghurts, fromage blanc, petits suisses.

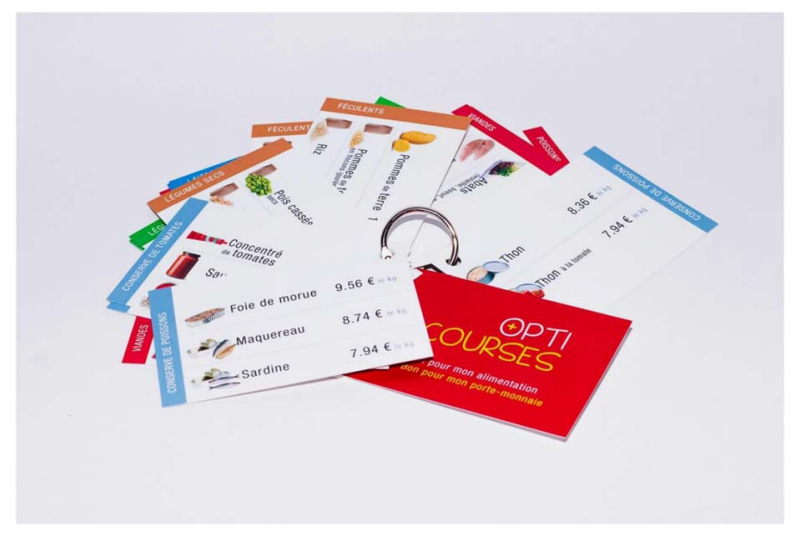

Fig. 2 Good Price Booklet distributed during Opticourses workshops (photo credits: Cédric Dubois)

booklet given their widely established health benefits ${ }^{(20)}$, even though they were not strictly foods of good nutritional quality and price (olive oil has SAIN:LIM lower than the median SAIN:LIM value of the table and walnuts have an average price over 2.5 times higher than the limit price of their group). Therefore, for these two foods, the booklet did not give a price but instead stated 'Although expensive, moderate consumption is good for your health'. It was not possible to include foods specific to certain culinary cultures in the booklet (e.g. plantain, sorghum, etc.), as average national prices in mainland France are often high. It was noted at the end of the booklet that 'Traditional basic foods from your culture are usually of good nutritional quality, and you probably know where to buy them at a good price'.

\section{Quantitative assessment of the relevance of in-booklet price}

Several trials were conducted and compared to test the suitability of the proposed method. It emerged that the choice of the median SAIN:LIM to identify foods of good nutritional quality in the table and the choice of the price tertile of each group to estimate in-booklet prices was the most suitable method to have a sufficient number of foods in each group as well as a realistic price value regarding prices observed on supermarket shelves. The tool was tested by the team and workshop participants. During the Opticourses intervention, 2386 purchases of foods with good nutritional quality and price were registered, of which $67 \cdot 1 \%$ were bought at a price lower than the in-booklet price (Table 3). When separately analysing foods as categorized by supermarket shelf, over half of the purchases made were below prices displayed in the booklet, except for processed meats (46.5\%), breads (8.3\%), and oils and fats (25.3\%). Note, however, that the booklet counted only a few foods in these three categories (due to their relatively low nutritional quality), resulting in few related purchases. 
Table 3 Proportion, by supermarket-shelf category, of purchases of the Good Price Booklet's foods bought at a price below the booklet price by Opticourses participants from socio-economically disadvantaged neighbourhoods of Marseille, France, 2012-2014

\begin{tabular}{|c|c|c|c|c|c|}
\hline \multirow[b]{2}{*}{ Supermarket-shelf category } & \multicolumn{2}{|c|}{ Price $(€ / \mathrm{kg})$} & \multirow[b]{2}{*}{ Total $n$} & \multicolumn{2}{|c|}{ Price below the booklet price } \\
\hline & Median & IQR & & $n$ & $\%$ \\
\hline Vegetables (fresh or frozen) & 1.5 & $1 \cdot 0-2 \cdot 0$ & 425 & 263 & 61.9 \\
\hline Fruit & 1.5 & $1 \cdot 0-2 \cdot 0$ & 373 & 219 & 58.7 \\
\hline Fish (fresh or frozen) & $5 \cdot 9$ & $4 \cdot 0-12 \cdot 0$ & 11 & 6 & 54.5 \\
\hline Meat (fresh or frozen) & $6 \cdot 8$ & $4.0-8 \cdot 8$ & 163 & 93 & $57 \cdot 1$ \\
\hline Processed meat & $9 \cdot 8$ & $7 \cdot 4-13 \cdot 3$ & 28 & 13 & 46.4 \\
\hline Eggs & 1.9 & $1 \cdot 9-2 \cdot 8$ & 130 & 97 & $74 \cdot 6$ \\
\hline Dairy & 0.9 & $0.6-1.5$ & 319 & 276 & 86.5 \\
\hline Bread & $3 \cdot 8$ & $2 \cdot 5-4.5$ & 12 & 1 & $8 \cdot 3$ \\
\hline Grains & 1.2 & $0.8-2 \cdot 0$ & 209 & 164 & 78.5 \\
\hline Potato & 1.0 & $0.6-1.7$ & 126 & 84 & $66 \cdot 7$ \\
\hline Legumes & $2 \cdot 0$ & $1 \cdot 3-2 \cdot 7$ & 37 & 27 & 73.0 \\
\hline Tinned vegetables & $2 \cdot 2$ & $1 \cdot 7-2 \cdot 8$ & 87 & 51 & 58.6 \\
\hline Tinned tomatoes & 1.6 & $0.6-2.1$ & 100 & 73 & 73.0 \\
\hline Tinned legumes & 1.8 & $1 \cdot 2-2 \cdot 7$ & 27 & 18 & $66 \cdot 7$ \\
\hline Tinned fish & 7.4 & $5 \cdot 8-9 \cdot 2$ & 39 & 24 & 61.5 \\
\hline Soup & 1.4 & $1.0-2.0$ & 6 & 4 & $66 \cdot 7$ \\
\hline Juice & 0.9 & $0.7-1.1$ & 141 & 116 & $82 \cdot 3$ \\
\hline Oils \& fats & 1.5 & $1.4-1.6$ & 95 & 24 & $25 \cdot 3$ \\
\hline Breakfast cereals* & - & & - & - & - \\
\hline Sweet products & 2.5 & $1.8-4.6$ & 9 & 5 & 55.6 \\
\hline Frozen potato & $1 \cdot 1$ & $0.8-1.4$ & 49 & 42 & 85.7 \\
\hline
\end{tabular}

$\mathrm{IQR}$, interquartile range.

*Not purchased by Opticourses participants.

None of the breakfast cereals listed in the booklet were purchased by the participants, and so we could not assess the relevance of the in-booklet price for this category. Percentages of purchases below prices displayed in the booklet were higher for foods for which the booklet prices were based on average national price rather than on limit price (i.e. up to 2.5 times cheaper than the average national price), suggesting that it was easier to find the former than the latter.

\section{Applicability of the Good Price Booklet within the framework of the Opticourses intervention}

One of the workshop's aims was to share experiences for buying food at lower prices. Participants exchanged useful tips, with some of them knowing where to buy at unbeatable prices (flea markets, stock clearance stores, the fish market at the end of the morning, etc.). These discussions gave contributors the opportunity to highlight several strategies such as substitutions between different food groups (e.g. purchasing less meat and more vegetables), intragroup substitutions (e.g. purchasing cheaper meats of higher nutritional quality) and 'price hunting' (e.g. for a given food, preferring low-cost foods over their brand-name equivalents). Thanks to the Good Price Booklet, the notion of 'good price' was no longer theoretical. As the Good Price Booklet was designed to be easily transportable in a handbag, it can be used directly in purchase situations: if the price displayed in the shop is below the booklet price for a given food, it is a bargain!

\section{Qualitative assessment of the Good Price Booklet}

All participants appreciated the quality of the discussions during the workshops. This was facilitated by the insight it gave into participants' concerns about the relationship between nutritional quality and food budget. The Good Price Booklet was praised by all participants interviewed (except for one person with reading difficulties), as well as by professionals. The tool, co-constructed with the workshop participants, was greatly appreciated and continued to be used more than a month after the workshops. Verbatim accounts recorded during interviews one month after the workshops include, for example:

'I use this tool [Good Price Booklet] when I go shopping, it's always in my bag. I buy products when they're cheaper than the price listed here. I mostly use it for vegetables when I go to Noailles [a popular fresh foods market, in the centre of Marseille] at the end of the market, as it's cheaper.'

'I do my shopping with the keyring [Good Price Booklet] and I buy when it's below the price listed, otherwise I buy something else.'

'I use this tool, it's handy. I buy a lot of bargains.'

'This month my husband had more time for shopping, so this tool helped him a bit.'

'I compare purchases with the Good Price Booklet, and I manage to find shops with cheaper prices. 
But I've always looked at prices - now I've got this tool, it motivates me to shop better.'

One participant did not use the booklet but explained that her financial constraints were less limiting:

'I prefer quality to a good price now that there are only two of us at home. The children don't live with us anymore so it's different, we can afford to choose quality.'

\section{Discussion}

The Good Price Booklet, designed to help recognize foods with good nutritional quality and price when grocery shopping, resulted from a co-construction using the desire of people with financial difficulties to have information on the 'good price' for foods and the theoretical work of the research team on the notion of foods with a good $\mathrm{NQP}^{(12)}$.

Two indicators - SAIN and LIM - were used to appreciate the nutritional quality of foods based on a limited number of nutrients (five qualifying nutrients and three disqualifying nutrients). This selection reflected a balance between the need to include nutrients that are of importance to public health and nutrient markers of other essential nutrients ${ }^{(21)}$. When implemented, the SAIN,LIM system was found to adequately discriminate foods according to their contribution to nutritionally adequate $\operatorname{diets}^{(19,22)}$. Several studies show that price is a major criterion in terms of food choices, and this is particularly true for people with a limited budget ${ }^{(23,24)}$. Managing a small food budget effectively requires a sound understanding of food choices. It is true that the foods we are advised to consume more of to protect our health, such as fruit, vegetables and fish, are more expensive sources of energy, whereas carbohydrates and high-fat and highsugar foods are cheap sources of energy ${ }^{(3)}$. Nevertheless, while studies on the cost of a balanced diet unequivocally show that it is more difficult to get a balanced diet with a small budget ${ }^{(7,25)}$, they also show that it is not impossible on the condition that food groups and good-NQP foods are chosen ${ }^{(12)}$. The nutritional quality of foods correlates positively with food prices (expressed in $€ / 418 \mathrm{~kJ}$ $(100 \mathrm{kcal})$ based on average national prices) ${ }^{(26)}$. This indicates that price structure is generally negative for nutritional balance, because the most expensive foods are often the most nutrient-dense. However, there is strong dispersion around this correlation line, which shows the existence of foods with higher NQP than others: for the same price, one can find foods of high and lower nutritional quality. In particular, legumes, vegetable oils, wholemeal cereal products, milk, plain yoghurt, eggs, poultry and some seafood (e.g. tinned sardines) have a higher NQP 'in absolute terms'. Conversely, other animal products and most fruits and vegetables (with exceptions, such as carrots, orange juice, etc.) emerge as too expensive to have a good $\mathrm{NQP}^{(6,11,12)}$. Giving priority to foods with a good NQP 'in absolute terms' makes it possible to create a nutritionally optimal diet for $€ 3 \cdot 50 / \mathrm{d}^{(12)}$.

Many studies have jointly addressed the notions of diet cost and diet quality ${ }^{(3)}$. Some have found that eating healthily does not necessarily cost more when foods with higher nutritional quality for their price are selected ${ }^{(8,12)}$. Above all, they highhlight that achieving higher-quality diets does not entail major changes in habitual dietary patterns but rather optimal choices in each food group (e.g. by preferring low-cost foods to their brand-name equivalents, or canned products to fresh ones) ${ }^{(9,10)}$. However, any effort to encourage a balanced diet for underprivileged populations mainly by promoting foods with good NQP 'in absolute terms' is potentially contentious: not only because many of them are rarely consumed and therefore not socially acceptable for everyone (as is the case for tinned sardines and giblets, for example) ${ }^{(27)}$ but also because, given the variability of prices, it is highly theoretical to claim categorically that a food has higher nutritional quality for its price in absolute terms. In this regard, during the Opticourses workshops, the theoretical list of foods with good NQP in absolute terms' quickly proved ill-adapted to the reality in the field. For example, participants challenged the relevance of the list because peppers were not included. The average national price of bell pepper is too high for it to qualify as a food with good NQP 'in absolute terms', but the fact is that many participants managed to find this highly nutritious food far cheaper than the average national price. Basing its work on these observations and discussions over food prices, the research team was able to develop the notion of a food's good price.

The Good Price Booklet was produced in a dynamic two-way interaction between research and fieldwork. Co-construction is recognized as a factor for success in actions to promote health ${ }^{(28,29)}$. When they are developed in interaction with the public for which they are designed, educational tools have a better chance of being adapted to people's real situation and thus getting used. This is the case for the Good Price Booklet, since the qualitative assessment showed that the tool was appropriated by participants who knew how to use it. Most participants appreciated the tool and continued to use it more than a month after the intervention, thus demonstrating that the tool meets participants' expectation to find foods of good nutritional quality at an affordable price relative to their food budget. Considering the socio-economically disadvantged situation of the study population, these results suggest that prices displayed in the booklet may remain appropriate for any other population, notwithstanding the fact that 'good price' is a budget-dependent concept. Scaling up effective implementation of this education tool requires adapting the methodology to the target population. The booklet must notably integrate specific food patterns and dietary habits which may vary according to 
population or country considered. In particular, the Opticourses intervention targeted a financially struggling population with diverse cultural backgrounds, which may have resulted in specific dietary habits. Booklet prices must also be adapted to domestic food prices and currency.

This tool has several limitations. First, it uses average national prices dating from 2006, well before the Opticourses intervention began. It would be desirable to frequently update the in-booklet prices. However, collecting robust average national prices of foods is still a challenge ${ }^{(16)}$. In France, researchers estimated average national prices to match with consumption data from the two national dietary surveys, i.e. INCA1 (1998-1999) and INCA2 (2006-2007). Furthermore, previous analyses carried out as part of the Opticourses intervention showed that participants purchased food at prices significantly lower than the 2006 average national prices ${ }^{(15)}$, which thus remain relevant within the framework of our intervention. Second, national prices may not directly reflect local prices which are influenced by many factors such as local markets or policies ${ }^{(16)}$. Third, exposure to food contaminants, a growing health concern ${ }^{(30)}$, is not captured by the SAIN, LIM calculation. Fourth, the definition of good nutritional quality in the current study - based on the median of foods' SAIN:LIM - is relative and depends on the number and type of foods included in the table. If the composition table contained more fruit and vegetables, for example, then the median SAIN:LIM value would increase and thus modify the foods of good nutritional quality selected. Groups of foods high in fat and/or sugar would be less represented. An analysis based on the medians of the SAIN:LIM of each group would allow for the selection of more foods in certain groups, but this choice was rejected here as since median values were hugely disparate depending on the group, some foods with high nutritional quality would be eliminated (e.g. certain fruits and vegetables) while others with lower nutritional quality would be selected (e.g. foods high in fats and sugars) due to the differences in nutritional quality of the groups to which they belong. To overcome these problems, one solution would be to adopt a non-relative definition of nutritional quality, such as its classification within the SAIN,LIM nutrient profiling system, which depends exclusively on the nutritional composition of each food, independent of the food group to which it belongs ${ }^{(19)}$. A final limitation concerns the methodology used to produce the booklet's prices, which could itself be considered arbitrary. However, several trials were conducted to test the realism of the findings obtained by means of the method adopted, and they confirmed the possibility of finding the foods presented in the booklet at a price cheaper than listed. The method developed here needs to be validated more thoroughly to assess the sensitivity of results to spatial and temporal variation in food databases and average national prices.

Various actors (departmental health education committees, family allowance offices, health insurance companies, dietitians, social workers, etc.) require adapted tools to address the issue of shopping and eating healthily on a low budget. The Opticourses Good Price Booklet enables them to move from theory to practice on purchasing food for a balanced diet on a low budget, and is an example of an educational tool produced through co-construction. The transferability of the Opticourses approach is currently being studied as part of a broader project in France. This will provide an opportunity to test the acceptability and benefits of Opticourses protocols and tools in different contexts in terms of target populations, organizations, areas, etc.

Health logos, nutritional information and even subsidies can give rise to unwanted effects and may be liable to increase social inequalities with regard to nutrition ${ }^{(31)}$. A positive nutritional logo exclusively indicating foods with a good NQP (by making them available, visible and attractive in shops) was found to direct purchases towards these foods ${ }^{(16)}$ and would be a concrete way to help consumers identify foods that enable them to reconcile nutrition and budget when they shop for food. Further research is now needed to investigate the effect on nutritional status of a positive logo scheme promoting goodNQP foods.

\section{Acknowledgements}

Acknowledgements: The authors would like to thank everyone involved in the 'demand' section of the Opticourses intervention: Hind Gaigi (project leader), MaluSéverine Gaubard and Audrey Maidon (contributors), Audrey Lesturgeon (administrator), Maëlle Robert, Joséphine Rohaut and Lucile Marty (students), Célia Chischportich (external evaluator) and Valérie Leblanc (graphic designer), as well everyone who participated in the workshops and all those who work in the organizations where the workshops were held. Financial support: After two innovative actions funded by the Agence régionale de santé Provence-Alpes-Côte-d'Azur (ARSPACA) in 2010 and 2011, Opticourses received funding for 2 years from the Institut National du Cancer (INCa), and since September 2014 has been funded by the ARS-PACA to study its transferability on a regional scale. The funding organizations had no role in the design, analysis or writing of this article. Conflict of interest: None. Authorship: N.D. and C.D. designed the study. N.D. provided databases essential for the research. N.D. provided methodological support for data analyses. C.D. and M.T. analysed data, performed statistical analysis and wrote the first draft of the manuscript. All authors had full access to data and revised and approved the manuscript for publication. N.D. and C.D. have primary responsibility for final content. Ethics of human subject participation: The protocol of the Opticourses education intervention was reviewed by the Comité de Protection des Personnes Sud-Méditerranée 
which stated that no institutional review board approval was necessary for this research. Written informed consent was obtained from all participants at enrolment and the trial was registered at clinicaltrials.gov as NCT02383875.

\section{References}

1. James WP, Nelson M, Ralph A et al. (1997) Socioeconomic determinants of health. The contribution of nutrition to inequalities in health. BMJ 314, 1545-1549.

2. Aggarwal A, Monsivais P, Cook AJ et al. (2011) Does diet cost mediate the relation between socioeconomic position and diet quality? Eur J Clin Nutr 65, 1059-1066.

3. Darmon N \& Drewnowski A (2015) The contribution of food prices and diet cost to socioeconomic disparities in diet quality: a systematic review and analysis. Nutr Rev $\mathbf{7 3}$, 643-660.

4. Andrieu E, Darmon N \& Drewnowski A (2006) Low-cost diets: more energy, fewer nutrients. Eur J Clin Nutr 60 , 434-436.

5. Townsend MS, Aaron GJ, Monsivais P et al. (2009) Lessenergy-dense diets of low-income women in California are associated with higher energy-adjusted diet costs. Am J Clin Nutr 89, 1220-1226.

6. Maillot M, Darmon N, Darmon M et al. (2007) Nutrientdense food groups have high energy costs: an econometric approach to nutrient profiling. J Nutr 137, 1815-1820.

7. Darmon N, Ferguson EL \& Briend A (2002) A cost constraint alone has adverse effects on food selection and nutrient density: an analysis of human diets by linear programming. J Nutr 132, 3764-3771.

8. Darmon N, Ferguson EL \& Briend A (2006) Impact of a cost constraint on nutritionally adequate food choices for French women: an analysis by linear programming. J Nutr Educ Behav 38, 82-90.

9. Cooper S \& Nelson M (2003) 'Economy' line foods from four supermarkets and brand name equivalents: a comparison of their nutrient contents and costs. J Hum Nutr Diet 16, 339-347.

10. Darmon N, Caillavet F, Joly C et al. (2009) Low-cost foods: how do they compare with their brand name equivalents? A French study. Public Health Nutr 12, 808-815.

11. Drewnowski A (2010) The Nutrient Rich Foods Index helps to identify healthy, affordable foods. Am J Clin Nutr $\mathbf{9 1}$, issue 4, 1095S-1101S.

12. Maillot M, Ferguson EL, Drewnowski A et al. (2008) Nutrient profiling can help identify foods of good nutritional quality for their price: a validation study with linear programming. J Nutr 138, 1107-1113.

13. Drewnowski A (2013) New metrics of affordable nutrition: which vegetables provide most nutrients for least cost? J Acad Nutr Diet 113, 1182-1187.

14. Darmon N (2010) Manger équilibré malgré la précarité (Balanced diet in spite of precarious conditions?). Soins 55, Suppl. 744, S10-S12.

15. Marty L, Dubois C, Gaubard MS et al. (2015) Higher nutritional quality at no additional cost among low-income households: insights from food purchases of 'positive deviants'. Am J Clin Nutr 102, 190-198.

16. Gamburzew A, Darcel N, Gazan R et al. (2016) In-store marketing of inexpensive foods with good nutritional quality in disadvantaged neighborhoods: increased awareness, understanding, and purchasing. Int J Behav Nutr Phys Act 13, 104.

17. Lee A, Mhurchu CN, Sacks G et al. (2013) Monitoring the price and affordability of foods and diets globally. Obes Rev 14, 82-95.

18. Bocquier A, Vieux F, Lioret S et al. (2015) Socio-economic characteristics, living conditions and diet quality are associated with food insecurity in France. Public Health Nutr 18, 2952-2961.

19. Darmon N, Vieux F, Maillot M et al. (2009) Nutrient profiles discriminate between foods according to their contribution to nutritionally adequate diets: a validation study using linear programming and the SAIN,LIM system. Am J Clin Nutr 89, 1227-1236.

20. Estruch R, Ros E, Salas-Salvado J et al. (2013) Primary prevention of cardiovascular disease with a Mediterranean diet. N Engl J Med 368, 1279-1290.

21. Tharrey M, Maillot M, Braesco V et al. (2017) From the SAIN, LIM system to the SENS algorithm: a review of a French approach to nutrient profiling. Proc Nutr Soc (Epublication ahead of print version)

22. Maillot M, Drewnowski A, Vieux F et al. (2011) Quantifying the contribution of foods with unfavourable nutrient profiles to nutritionally adequate diets. Br J Nutr $\mathbf{1 0 5}$, $1133-1137$.

23. Wiig K \& Smith C (2009) The art of grocery shopping on a food stamp budget: factors influencing the food choices of low-income women as they try to make ends meet. Public Health Nutr 12, 1726-1734.

24. Waterlander WE, de Mul A, Schuit AJ et al. (2010) Perceptions on the use of pricing strategies to stimulate healthy eating among residents of deprived neighbourhoods: a focus group study. Int J Behav Nutr Phys Act 7, 44.

25. Drewnowski A, Darmon N \& Briend A (2004) Replacing fats and sweets with vegetables and fruit - a question of cost. Am J Public Health 94, 1555-1559.

26. Darmon N, Darmon M, Maillot M et al. (2005) A nutrient density standard for vegetables and fruits: nutrients per calorie and nutrients per unit cost. J Am Diet Assoc 105, 1881-1887.

27. Maillot M, Darmon N \& Drewnowski A (2010) Are the lowest-cost healthful food plans culturally and socially acceptable? Public Health Nutr 13, 1178-1185.

28. World Health Organization (2009) Interventions on Diet and Physical Activity: What Works. Summary Report. Geneva: WHO.

29. Molleman GRM, Peters LWH, Hommels LH et al. (2006) Project quality rating by experts and practitioners: experience with Preffi 2.0 as a quality assessment instrument. Health Educ Res 21, 219-229.

30. Hussain MA (2016) Food contamination: major challenges of the future. Foods 5, issue 2, E21.

31. Darmon N, Lacroix A, Muller L et al. (2014) Food price policies improve diet quality while increasing socioeconomic inequalities in nutrition. Int J Behav Nutr Phys Act 11, 66. 